\title{
QUALITATIVE ANALYSIS OF DIGITAL DERMATOGLYPHICS IN A SMALL PATIENTS GROUP IN BOSNIA AND HERZEGOVINA
}

\author{
Jasmin Musanovic ${ }^{1}$, Azra Metovicㄹ, Faruk Husremovic 3 , Samir Bejic ${ }^{4}$, Aldina Haskovic ${ }^{5}$, Aida Babic 6 , Senad Sljuka7, Orhan Lepara ${ }^{8}$ \\ 1 Department of Biology and Human Genetics, Medical Faculty of Sarajevo, University of Sarajevo, Sarajevo, Bosnia and Herzegovina. \\ 2Department of Biology and Human Genetics, Medical Faculty of Sarajevo, University of Sarajevo, Sarajevo, Bosnia and Herzegovina. \\ 3 Department of Urology, Cantonal Hospital, Zenica, Bosnia and Herzegovina. \\ ${ }^{4}$ Health Centre of Sarajevo Canton, Sarajevo, Bosnia and Herzegovina. \\ ${ }^{5}$ Faculty of Science, University of Sarajevo, Sarajevo, Bosnia and Herzegovina. \\ ${ }^{6}$ Faculty of Science, University of Sarajevo, Sarajevo, Bosnia and Herzegovina. \\ ${ }^{7}$ Department of General Biology, University of Sarajevo, Sarajevo, Bosnia and Herzegovina. \\ ${ }^{8}$ Medical Faculty of Sarajevo, Department of Human Physiology, University of Sarajevo, Sarajevo, Bosnia and Herzegovina.
}

\begin{abstract}
BACKGROUND

Dermatoglyphics refers to epidermal ridges that typically form under genetic control in the early stage of development. The aforesaid skin ridges are very likely to be influenced by various external, i.e. environmental circumstances in the course of the first trimester of pregnancy. In other words, it implies that the genetics message contained in the normal or abnormal genome is decoded throughout this particular period and likewise, reflected by dermatoglyphics. Dermatoglyphic pattern has been studied in various diseases. The main idea of this paper was to determine differences of fingerprints patterns in breast cancer patients and healthy women.
\end{abstract}

\section{METHODS}

The study was conducted on 50 histopathologically confirmed breast cancer women and 50 healthy women without family history of diagnosed breast cancer. The prints were analyzed by qualitative methods like arches, loops, whorls. The differences of qualitative dermatoglyphic patterns were tested for their significance using the Chi-square test and Fisher's exact test. A p-value of $<0.05$ was considered statistically significant.

\section{RESULTS}

It was observed that six or more loops in the fingerprint pattern were statistically significant among the control group as compared to women with breast cancer. A pattern of six or more loops can be used as an indicator during calculation of the risk of the breast cancer. The difference between other parameters was not statistically significant.

\section{CONCLUSIONS}

It can be concluded in qualitative dermatoglyphic analysis that women with reduced number of digital loops tend to develop breast cancer. Therefore, the occurrence of breast cancer can be predicted and dermatoglyphics can be used as a non-invasive, anatomical marker and prediction tool to detect women with increased risk for breast cancer, who then can be subjected to timely mammography.

HOW TO CITE THIS ARTICLE: Musanovic J, Metovic A, Husremovic F, et al. Qualitative analysis of digital dermatoglyphics in a small patients group in bosnia and herzegovina. J. Evolution Med. Dent. Sci. 2019;8(17):1415-1418, DOI: $10.14260 /$ jemds $/ 2019 / 315$

\section{BACKGROUND}

Dermatoglyphics refers to epidermal ridges that typically form under genetic control in the early stage of development. The aforesaid skin ridges are very likely to be influenced by various external, i.e. environmental circumstances in the course of the first trimester of pregnancy. In other words, it implies that the genetics message contained in the normal or abnormal genome is decoded throughout this particular period and likewise, reflected by dermatoglyphics.(1) It is believed that they may represent different genetically determined congenital abnormalities. Several genes are involved in the inheritance of the dermal traits.(2)

'Financial or Other Competing Interest': None.

Submission 29-12-2018, Peer Review 15-04-2019,

Acceptance 22-04-2019, Published 29-04-2019.

Corresponding Author:

Faruk Husremovic,

Crkvice 67, Zenica-72000.

E-mail: faruk.husremovic@gmail.com

DOI: $10.14260 /$ jemds $/ 2019 / 315$
The correspondence between predilection of cancer and dermatoglyphics patterns has been recorded in previously conducted studies.(3) Breast cancer is the most common malignant tumor in women around the world and makes more than $20 \%$ of all malignant diseases in female population. In the Federation of Bosnia and Herzegovina, breast cancer is the most common cancer. Two tumor suppressor genes BRCA1 and BRCA2 are linked to the occurrence of family breast cancer. The main role of these genes is repairing DNA damage and maintaining the genome integrity. Loss of their function contributes to genomic instability. Women with BRCA1 and BRCA2 mutations have a poorer prognosis and shorter survival than those without mutations on these genes. ${ }^{(4)}$ Inherited breast cancers form the total of $5-10 \%$ of all breast tumor cases within which around $90 \%$ of inherited breast tumors include mutation of the BRCA1/2 genes. ${ }^{(5)}$

The study of dermatoglyphics can serve as a noninvasive, anatomical marker and a predictor tool to determine the individuals with breast cancer.(6) 
The main aim of this paper was to determine the differences in dermatoglyphic patterns in women with breast cancer and healthy women.

\section{Aims and Objectives}

1. To determine qualitative differences in digital dermatoglyphic patterns in women with breast cancer compared to normal women.

2. To use the results of this study as one of the diagnostic parameters for early detection of breast cancer development.

\section{METHODS}

\section{Sample Size}

The convenience sampling size was determined according to the world's similar studies. Bosnia and Herzegovina do not have statistic evidence about the total number of women with breast cancer. That is why our sample is made up by convenience, made up of Bosnian Herzegovinian population and according to very low statistical and data base evidence. All examinees were provided with appropriate information about aims, methods and purpose of this research. Ethical anonymity was provided by filling in the questionnaire form. After obtaining permission from the Ethics Committee, inform consent form was taken from the patients. This case control study included total 100 patients, 50 histopathologically confirmed breast cancer women and 50 healthy women who were informed about the procedure in detail and data comprising of age and address were taken in Bosnia and Herzegovina in 3 cities (Kakanj, Zenica, Visoko). Those cities were not included in our previous studies(6) and had no complete statistical evidence. All samples are the result of volunteer participation.

\section{Case group}

In the patients (Case) group were 50 women in the age group of 18-80, with histopathologically confirmed breast cancer. All women were breast cancer association members from those cites.

All examinees had no history of any other disease or disorders especially genetically based.

Patients in the terminal phase were not estimate.

\section{Control group}

The control group were consisted of 50 healthy women randomly selected volunteers age ranged from 18-80, selected by the Department of Biology and Human Genetics, Medical School, University of Sarajevo. All women had no familiar history of any other disease or disorders especially genetically based.

Inclusion and exclusion criteria were followed for this group as well.

\section{Inclusion Criteria}

1. 50 histopathologically confirmed female breast cancer patients aged 18 years and over.

2. 50 female control group individuals with no history of cancer or any other genetic disorders.

3. Citizenship of Bosnia and Herzegovina.

4. Signed informed consent.

\section{Exclusion Criteria}

1. Diagnosis of other type of cancers - medically confirmed

2. Disability linked to the fingers of both hands.

3. Disability linked to the palm of both hands.

4. The presence of genetically based disorders or diseases. Collecting the fingerprints of both hands (Right and Left) was done by staining them (Printake). Taking a fingerprint is done by pressing all the areas of fingers in sequence on a white piece of paper sheet. The cases were labeled on the sheets with all their relevant data.

\section{Statistical Analyses}

Statistical analysis was performed using IBM SPSS Statistics version 21.0. Data are presented as absolute numbers and as percentages as well as odds ratios (ORs) and marginal effects with $95 \%$ CI. In the analysis of the dependence between categorical variables, chi-square test and Fisher's exact test were performed. Finally, logistic regression analysis was used to assess the predictors of the disease. A p-value of $<0.05$ was considered statistically significant.

Study was done for Qualitative Analysis of Digital Dermatoglyphics

\section{Dermatoglyphics: Qualitative Analyses of Fingers-}

\section{Arch}

Labelled as an area without drawings.

\section{Tented Loop}

Labelled as $\mathrm{T}$ formation with triradius in the center of the drawing classified as half of ulnar and half of radial loop.

\section{The Ulnar Loop}

Labelled as $U$ pattern runs in the direction of radius, the central part and triradius are on the radial side; topologically is classified as the presence of radial component (value 2) and absence of ulnar (value 0 ), and traditionally is labelled by U.

\section{The Radial Loop}

Labelled as R pattern runs in the direction of ulna, and the triradius and the central part are located on the ulnar side. Topologically is classified as the presence of an ulnar component (value 2) and the absence of radial (value 0 ).

\section{Whorl}

Labelled as W is a concentric or spiral drawing followed by two triradii. Topologically: as the presence of ulnar and radial loops. This category of drawings also belongs to the double loops, as they are always accompanied by two triradii.(6)

\section{RESULTS}

From the statistical analysis the following results were obtained. Results of the research of qualitative analysis of dermatoglyphics breast carcinoma patients were compared with the results obtained in the control group.

Out of the 1000 fingerprints studied, the cancer breast patients had $30 \%$ whorls, $62.4 \%$ loops and $7.6 \%$ arches whereas the control group had $28.6 \%$ whorls, $66.8 \%$ loops and $4.6 \%$ arches (Fig. 1). We found that the arches were least represented. There was not any statistically 
significant difference between these two groups regarding the fingerprint patterns.

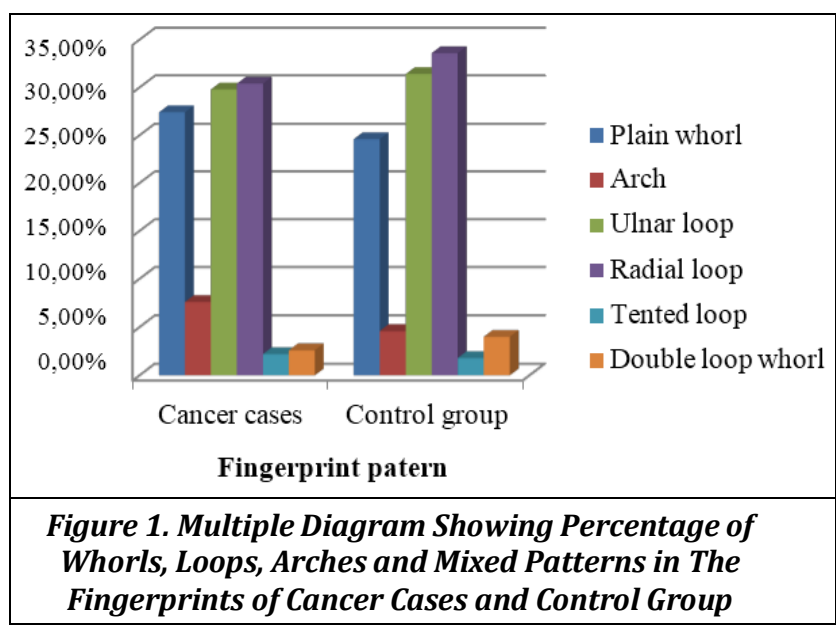

Analysis indicated there was no statistically significant difference in the presence of six or more whorls between the breast cancer patients and control group (Fisher's exact test: $\chi 2=0.78, p=0.500 ; p>0.05$ ) (Table 1 ).

It was observed that six or more loops in the finger print pattern were statistically significant among the controls as compared to breast cancer patients (Fisher's exact test: $\chi 2=3.934, \mathrm{p}=0.038 ; \mathrm{p}<0.05$ ) (Table 2). Pattern of 6 or more loops is the indicator in calculating the risk of breast cancer.

In the study group, the frequency of arches was $15 \%$, while $35 \%$ had no arches. In the control group, frequency of arches was $10 \%$, while $40 \%$ women had no arches. There was no statistically significant difference in the frequency of arches between the control and the study group (Fisher's exact test: $p=0.173 ; p>0.05$ ) (Table 3 ).

In study group, the frequency of mixed patterns was $6 \%$, while $44 \%$ women had no mixed patterns. In the control group, which consisted of 50 women, the frequency of mixed patterns was $11 \%$, while remaining $39 \%$ women did not have any mixed patterns. There was no statistically significant difference in the frequency of mixed patterns between the control and the study group (Fisher's exact test: $p=0.143, p>0.05$ ) (Table 4).

\begin{tabular}{|c|c|c|c|c|c|}
\hline $\begin{array}{l}\text { Fingerprint } \\
\text { Pattern }\end{array}$ & $\begin{array}{l}\text { Cancer } \\
\text { Cases }\end{array}$ & $\begin{array}{l}\text { Control } \\
\text { Group }\end{array}$ & Total & $\chi^{2}$ & p Value \\
\hline Whorls $\geq 6$ & 7 & 8 & 15 & \multirow{3}{*}{0.78} & \multirow{3}{*}{$\mathrm{p}>0.05$} \\
\hline Whorls $<6$ & 43 & 42 & 85 & & \\
\hline Total & 50 & 50 & 100 & & \\
\hline
\end{tabular}

\begin{tabular}{|c|c|c|c|c|c|}
\hline $\begin{array}{c}\text { Fingerprint } \\
\text { Pattern }\end{array}$ & $\begin{array}{c}\text { Cancer } \\
\text { Cases }\end{array}$ & $\begin{array}{c}\text { Control } \\
\text { Group }\end{array}$ & Total & $\chi \mathbf{2}$ & $\mathbf{p}$ Value \\
\hline Loops $\geq 6$ & 31 & 40 & 71 & & \\
\hline Loops $<6$ & 19 & 10 & 29 & 3.934 & $\mathrm{p}<0.05$ \\
\hline Total & $\mathbf{5 0}$ & $\mathbf{5 0}$ & $\mathbf{1 0 0}$ & & \\
\hline Table 2. Association Between Presence of More Than Six \\
Loops and Carcinoma of Breast \\
\hline
\end{tabular}

\begin{tabular}{|c|c|c|c|c|c|}
\hline $\begin{array}{c}\text { Fingerprint } \\
\text { Pattern }\end{array}$ & $\begin{array}{c}\text { Cancer } \\
\text { Cases }\end{array}$ & $\begin{array}{c}\text { Control } \\
\text { Group }\end{array}$ & Total & $\boldsymbol{\chi} \mathbf{2}$ & $\mathbf{p}$ Value \\
\hline Arches & 15 & 10 & 15 & & \\
\hline No Arches & 35 & 40 & 85 & 1.33 & $\mathrm{p}>0.05$ \\
\hline Total & $\mathbf{5 0}$ & $\mathbf{5 0}$ & $\mathbf{1 0 0}$ & & \\
\hline Table 3. Frequency of Arches in The Control and Breast \\
Cancer Group \\
\hline
\end{tabular}

\begin{tabular}{|c|c|c|c|c|c|}
\hline $\begin{array}{c}\text { Fingerprint } \\
\text { Pattern }\end{array}$ & $\begin{array}{c}\text { Cancer } \\
\text { Cases }\end{array}$ & $\begin{array}{c}\text { Control } \\
\text { Group }\end{array}$ & Total & $\boldsymbol{\chi} \mathbf{2}$ & $\mathbf{p}$ Value \\
\hline Mixed & 6 & 11 & 15 & & \\
\hline No Mixed & 44 & 39 & 85 & \multirow{2}{*}{1.772} & $\mathrm{p}>0.05$ \\
\hline Total & $\mathbf{5 0}$ & $\mathbf{5 0}$ & $\mathbf{1 0 0}$ & & \\
\hline Table 4. Frequency of Mixed Patterns in The Control and \\
Breast Cancer Group \\
\hline
\end{tabular}

From the observed qualitative parameters, it was found that only whorls are a significant negative predictor of the disease 0.37 (0.15-0.89), while the number of loops; 0.18 (0.89-3.96) and arches, 1.04 (0.47-2.29) were not significant predictors of the disease.

\section{DISCUSSION}

Breast cancer is one of the most common malignant diseases among women in the world. According to NCRR (National cancer registry program) in 2008 , about $25 \%$ of all cancer cases were breast cancer. With increasing natality, it is important to develop methods for identifying individuals who are at risk or already have a certain disease. The use of dermatoglyphics, as presented in this paper, represents a unique and inexpensive approach of identification of such individuals.

In this paper, it is found that there is no significant difference between control and breast cancer group regarding fingerprint patterns (whorl, arch, loops and mixed figures). The highest frequency was observed for loops, then for whorls, and the least for arches, which was supported by Al.Araji 2003(7) who found the highest percentage of loops, then whorls and arches. Sariri et al 2012(8) found that the pattern of loops was most common in both examined groups, followed by whorls.

Statistically significant difference was not observed in the pattern of 6 or more whorls between these two groups, correlating with the results of the research by Natekar et al 2006(9), who found that the presence of more than 6 whorls is significantly negatively associated with carcinoma of breast. It appears that $>6$ whorls have a protective effect for breast cancer. This finding was in contrast to Lavanya et al 2012(10) study which reported significant difference regarding pattern of 6 or more whorls. Therefore, the percentage of whorls is higher in breast cancer group compared to the control. Chintamani et al 2007(11) also found that a pattern of 6 or more whorls was statistically significant among breast cancer patients compared to controls, which correlates with the results of research carried out by Seltezer 1982,(12) who observed that women with 6 or more whorls, have $95 \%$ chance to have a cancer or are at high risk of getting it. King Mc et al 1980(13), Huang and Mi 1987(14) and Sukre et al 2012(15) observed that the pattern of whorls is more common in breast cancer patients compared to controls. Abbasi et al 2006(16) found more whorls (6 out of 10) in breast cancer 
patients compared to controls. However, between study group and highly risk group there was not any statistical significance for more than 6 whorls. These results are consistent with the results of Chintamani et al 2007(11) and Fulari et al 2012,(17) who also showed an increase in the number of whorls in breast cancer patients.

Statistically significant difference was observed in pattern of 6 or more loops in control group compared to women with breast cancer, which was in contrast to Huang and Mi 1987(14) who found more loops in breast cancer patients compared to controls, which is consistent with the results of Chintamani et al 2007,(11) who also observed more loops in the patients. Natekar et al 2006(9) also concluded that females whose fingerprint patterns had more than six loops, had 46 times higher risk of developing breast cancer when compared to controls. Bierman et al 1988(18) and Sridevi 2010(19) observed that ulnar loops were significantly associated with breast cancer. On the other hand, Fulari et al 2012(17) found a lower percentage of ulnar loops in breast cancer patients compared to controls, which is consistent with the results obtained by Sukre et al 2012.(15)

Significant statistical difference was not observed in the frequency of arches between the control and the study group, which is not corresponding to the results of Ajeena 2015(20) whose results showed the following. Increased number of arches was observed in both hands in breast cancer patients, these results were supported by Raizada et al 2013(21) who found an increasing number of arch patterns in both hand in breast cancer patients in comparison with the control.

\section{CONCLUSIONS}

It can be concluded in qualitative dermatoglyphic analysis that women with reduced number of digital loops tend to develop breast cancer. Therefore, the occurrence of breast cancer can be predicted and dermatoglyphics can be used as a non-invasive, anatomical marker and prediction tool to detect women with increased risk for breast cancer, who then can be subjected to timely mammography.

\section{REFERENCES}

[1] Moore K, Persaud TV. The developing human. 7th edn. Saunder Publications 2004:492-3.

[2] Mathew L, Hegde AM, Rai K. Dermatoglyphic peculiarities in children with oral clefts. J Indian Soc Pedod Prev Dent 2005;23(4):179-82.

[3] Ad Teletar MA. Cancer and dermatoglyphic. Lancet 1980:861.

[4] Larsen MJ, Thomassen M, Gerdes AM, et al. Hereditary breast cancer: clinical, pathological and molecular characteristics. Breast Cancer (Auckl) 2014;8:145-55.

[5] Sakorafas GH, Tsiotou AG. Genetic predisposition to breast cancer: a surgical perspective. Br J Surg 2010;87(2):149-62.

[6] Musanovic J, Metovic A, Pepic E, et al. Predictive values of quantitative analysis of finger and palmar dermatoglyphics in patients with breast cancer for
Bosnian-Herzegovinian population. J Evolution Med Dent Sci 2018;7(24):2855-60.

[7] Al-Araji SM. Dermatoglyphic studies in breast cancer. University of Babylon College of Medicine 2003:1-3.

[8] Sariri E, Kashanian M, Vahdat M, et al. Comparison of the dermatoglyphic characteristics of women with and without breast cancer. The European Journal of Obstetrics \& Gynecology and Reproductive Biology 2012;160(2):201-4.

[9] Natekar PE, DeSouza FM, Motghare DD, et al. Digital dermal patterns in carcinoma of breast. Anthropologist 2006;8(4):251-4.

[10] Lavanya J, Saraswathi P, Vijayakumar J, et al. Analysis of dermatoglyphic traits in patients with breast cancer. Journal of pharmaceutical and Biomedical Sciences 2012;23(23):1-3.

[11] Chintamani R, Khandelwal R, Mittal A, et al. Qualitative and quantitative dermatoglyphic traits in patients with breast cancer: a prospective clinical study. BMC Cancer 2007;7:44.

[12] Seltzer MH, Plato CC, Engler PE, et al. Digital dermatoglyphics and breast cancer. Breast Cancer Res Treat 1982;2(3):261-5.

[13] King MC, Go RC, Elston RC, et al. Allele increasing susceptibility to human breast cancer may be linked to the glutamate pyruvate transaminase locus. Science 1980;208(4442):406-8.

[14] Huang CM, Mi MP. Digital dermal patterns in breast cancer. Proc Natl Sci Counc Repub China B 1987;11(2):133-6.

[15] Sukre SB, Laeeque $M$, Mahajan A, et al. Dermatoglyphics in identification of women either with or at risk of breast cancer. International J Basic Medical Science 2012;3(5):160-5.

[16] Abbasi S, Einollah N, Dashti N, et al. Study of dermatoglyphic patterns of hands in women with breast cancer. Pakistan Journal of Medical Sciences 2006;22(1):18-22.

[17] Fulari SP, Pirzade MM, Jadhav A. Study of dermatoglyphics in breast cancer. National Journal of Medical Sciences 2012;1(1):29-32.

[18] Bierman HR, Faith MR, Stewart ME. Digital dermatoglyphics in mammary cancer. Cancer Invest 1988;6(1):15-27.

[19] Sridevi NS, Delphine Silva CR, Kulakrni R, et al. Palmar dermatoglyphics in carcinoma breast of Indian women. Rom J Morphol Embryol 2010;51(3):547-50.

[20] Ajeena EH. Study The advantage of dermatoglyphics in detecting women with breast cancer. Al-Kufa University Journal for Biology 2015;7(3):1-5.

[21] Raizada A, Johri V, Ramnath T. A cross-sectional study on the palmar dermatoglyphics in relation to carcinoma breast patients. J Clin Diagn Res 2013;7(4):609-12. 